\title{
Impactos de Longo Prazo de Reformas Fiscais sobre a Economia Brasileira
}

\author{
Pollyana Jucá Santana*, Tiago V. de V. Cavalcanti ${ }^{\dagger}$, Nelson Leitão \\ Paes $\ddagger$
}

Conteúdo: 1. Introdução; 2. Gasto Público Brasileiro; 3. O Modelo; 4. Resultados;

5. Considerações Finais; A. Anexo - Análise de Sensibilidade dos Parâmetros.

Palavras-chave: Consumo do Governo, Investimento Público, Bem-estar, Carga tributária.

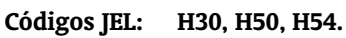

Este trabalho objetiva analisar o impacto de uma redução da carga tributária brasileira e aumento do investimento público, empregando um modelo de equilíbrio geral com crescimento exógeno, calibrando o modelo com dados de 2010. Os resultados sugerem que o consumo das administrações públicas é elevado e que o investimento público está abaixo do ideal. Simulações de política fiscal sugerem que apenas a redução da carga tributária não é favorável para a economia, mas a elevação do investimento público provocaria grandes alterações no nível de capital e bem-estar, bem como elevação real de arrecadação, apesar da queda da carga tributária.

This paper aims to analyze the impact of a reduction in Brazilian tax burden and increasing public investment, using a general equilibrium model with exogenous growth, calibrating the model with data from 2010. The results suggest that the current government spending is high and public investment is less than optimal. Simulations in fiscal policy suggest that only tax reduction is not good for the economy, but the increase in public investment would lead to major changes in the level of capital and welfare, and raising real revenue, despite lower tax burden.

\section{INTRODUÇÃO}

O objetivo principal deste trabalho é analisar a relação entre os gastos públicos no Brasil e seu impacto sobre a economia, estimando qual deveria ser o consumo público, através de um exercício econométrico, e o gasto ótimo em investimento, a partir de um modelo de crescimento exógeno. A

\footnotetext{
*Doutoranda em Economia pelo PIMES-UFPE. Endereço para correspondência: Rua Estevão de Sá, 390, Bloco 1, Apto. 103 Várzea, CEP 50740-270 - Recife-PE. E-mail: pollyanajs@yahoo.com.br

${ }^{\dagger}$ Professor do Departamento de Economia da UFPE.

${ }_{\ddagger}^{\ddagger}$ Professor do Departamento de Economia da UFPE.
} 
partir desses resultados, procede-se a simulações para avaliar os efeitos de alteração dos gastos públicos sobre a acumulação de capital e sobre o bem-estar.

A investigação dos efeitos da presença do Estado na economia vem sendo alvo de pesquisas teóricas e empíricas que buscam analisar o impacto do gasto público no crescimento econômico e no bem-estar, sendo que a maioria considera que o gasto em infra-estrutura (investimento público) é o único gasto produtivo e seria responsável por aumentar a produtividade dos fatores privados. Entretanto, esse efeito positivo gerador de externalidades benéficas à economia tem limite, pois esse gasto é financiado por impostos distorcivos que diminuem a eficiência da alocação dos recursos.

A primeira contribuição a esse debate surge com a chamada "Lei de Wagner", do final do século dezenove, que teoriza que os bens públicos são bens superiores, sendo que o gasto público como proporção do Produto Interno Bruto (PIB) cresceria de acordo com o desenvolvimento das nações. Mas é Samuelson (1954) que chama a atenção para a questão de qual deveria ser o gasto ótimo do governo, considerando os bens públicos como parte integrante da cesta de consumo das famílias. Já Barro (1990) modifica a forma de avaliar o gasto ótimo, considerando que este seria um insumo essencial na produção.

Aschauer (1989) é o pioneiro em estudar empiricamente a relação entre gasto produtivo e crescimento econômico, e encontra que gastos com infra-estrutura (rodovias, aeroportos, entre outros) contribuem para a elevação da produtividade do setor privado nos Estados Unidos. Barro (1989) estende tal análise utilizando dados cross-country para 72 países e seus resultados demonstram que gastos correntes são inversamente e investimentos públicos positivamente correlacionados com crescimento econômico. Outros autores como Easterly e Rebelo (1993) encontram resultados semelhantes.

Em relação à economia brasileira, Ferreira e Malliagros (1998) investigam a correlação entre investimento público em infra-estrutura e crescimento econômico no período de 1950/95 e encontram evidências de forte correlação positiva. Outros dois trabalhos empíricos para a economia brasileira devem ser citados. O primeiro é um estudo de Cândido Jr (2001), que conclui que a proporção de gasto público no Brasil está acima do seu nível ótimo, apesar da externalidade positiva do gasto com investimento. O outro é Assis e Dias (2004) que procedem a uma análise similar a de Cândido Jr (2001), mas utilizam um modelo auto-regressivo vetorial (VAR) na análise econométrica, com dados anuais de 1951 a 2000, e concluem que choques na razão capital público/capital privado, carga tributária e nível tecnológico exercem efeitos cíclicos sobre a taxa de crescimento do produto no Brasil e que a carga tributária causa impacto negativo sobre a taxa de crescimento da economia brasileira quando ultrapassa o nível ótimo de $25 \%$ do produto.

Outra linha de pesquisa empírica utiliza modelos de crescimento exógeno investigando alterações em variáveis de interesse, como produto, capital e bem-estar que seriam causadas por mudanças na política fiscal, tanto alterações dos gastos quanto de arrecadação. Um importante trabalho nessa linha é de Ferreira e Nascimento (2006) que levanta a questão da queda do investimento público nos últimos anos, e utilizando um modelo de crescimento exógeno faz um exercício de simulação para verificar as implicações de um retorno aos níveis de investimento público da década de 1960-80 concluindo que esta mudança seria benéfica para a economia brasileira, desde que o financiamento fosse por uma redução do gasto corrente. Por fim, Ferreira e Araújo (1999) e Paes e Bugarin (2006a), utilizando o mesmo instrumental de Ferreira e Nascimento (2006) analisam os efeitos na economia brasileira de uma reforma tributária, mas não alteram o gasto público, este se ajustaria à nova carga tributária. Esta é outra forma de analisar a diminuição do Estado brasileiro, uma vez que podemos avaliar o tamanho do Estado tanto pelos gastos quanto pela carga tributária.

Este trabalho procura contribuir para o debate acerca da presença do Estado na economia ao inserir o fator capital público na função de produção, como em Ferreira e Nascimento (2006), mas diferenciando da análise destes autores ao estimar qual deveria ser o gasto corrente do governo e qual o gasto ótimo em investimento. Também foram realizadas simulações a fim de analisar a dinâmica de variáveis de interesse (produto, consumo, capital, bem-estar) em cenários alternativos de política fiscal.

Mais especificamente, este trabalho objetiva encontrar um nível de gasto público corrente compatível com a realidade do país, através de um exercício empírico que compara a economia brasileira com as 
demais economias; encontrar um gasto ótimo em infra-estrutura utilizando um modelo de crescimento exógeno, sendo os fatores produtivos o capital privado, trabalho e o capital público, sendo a forma de financiamento do governo taxação sobre a renda do capital, do trabalho e sobre o consumo, calibrando o modelo com dados da economia brasileira para 2010 e realizando simulações dos parâmetros fiscais.

Os resultados encontrados sugerem que o consumo final das administrações públicas deveria ser menor que o atual (entre $16 \%$ e $18,50 \%$ do PIB ao invés dos atuais $20 \%$ de 2010 ) e que o governo deveria gastar em investimentos em torno de $3,75 \%$ do PIB, valor superior ao dispêndio público em formação de capital fixo de 1,89\% do PIB (média 1995-2006).

Em relação às simulações, os resultados indicam que apenas a redução do consumo público com consequente queda da tributação não é muito favorável para a economia, pois não altera significativamente a taxa de investimento nem o bem-estar das famílias, sendo prejudicial ao setor público que reduziria seu consumo em mais de $8 \%$. Mas ao elevar o investimento público, os resultados sugerem grandes alterações no nível de capital e bem-estar, bem como elevação real de arrecadação, apesar da queda da carga tributária.

Esse trabalho contempla, além desta introdução, outras quatro seções. A segunda seção faz uma comparação do Brasil com outros países, levantando a discussão sobre tamanho do governo brasileiro comparado com outras nações. A terceira apresenta o modelo empregado, bem como a metodologia para a realização das simulações, a seção quatro discute os principais resultados encontrados e, por fim, na última, têm-se as considerações finais.

\section{GASTO PÚBLICO BRASILEIRO}

\subsection{Investimento público ${ }^{1}$}

O Estado brasileiro exerceu durante muito tempo o papel de agente produtor responsável não só pelos serviços públicos, mas também pela produção de setores chaves para o desenvolvimento do país, sendo que o investimento público como proporção do PIB era muito mais elevado que o atual. $O$ investimento do setor público chegava a quase $4,50 \%$ do PIB em 1970, mas essa situação se modificou a partir de então, e o gasto produtivo teve trajetória oposta dos demais gastos públicos, oscilando entre 1,43 e $2,42 \%$ do PIB no período mais recente (1995-2006). De acordo Gremaud et alii (2004) essa redução ocorreu, pois a partir de 1980 os compromissos do Estado se tornaram maiores, com elevação dos gastos nas áreas sociais, sistema previdenciário, dívidas e encargos entre outras responsabilidades, e a concorrência entre essas diversas formas de alocação dos recursos públicos fizeram com que os gastos produtivos fossem reduzidos.

Além da questão das finanças públicas, questões microeconômicas de eficiência também impulsionaram essa alteração. A privatização do setor de telecomunicações foi benéfica para a sociedade, pois trouxe competição para o setor, aumentando a eficiência e o acesso da população a esses serviços. As empresas siderúrgicas, químicas e petroquímicas também foram beneficiadas com aumento da produtividade (Anuatti-Neto et alii, 2005). Por outro lado, a infraestrutura (sistema de água e esgoto, portos, aeroportos, transportes), imprescindível no desenvolvimento do país, não foi privatizada em sua maioria, e encontra-se em grande parte sucateado. Segundo Ferreira e Nascimento (2006) o gasto direto com rodovias de 1990 a 1995 foi um quinto do gasto realizado no período de 1970-75, sendo que hoje esse gasto não ultrapassa $0,1 \%$ do PIB.

\footnotetext{
${ }^{1}$ Consideramos investimento público a formação bruta de capital fixo das administrações públicas, não considerando o investi-
} mento das empresas estatais. 


\subsection{Consumo final das administrações públicas}

De 1930 até o final da década de 70 a grande preocupação do governo foi promover o desenvolvimento do país, interferindo fortemente na atividade econômica e utilizando todas as políticas públicas (monetária, fiscal, creditícia, entre outras) para tal fim. A preocupação era obter os recursos necessários para investir e gerenciar o endividamento, o consumo final das administrações públicas tinha papel secundário nas discussões do setor público. A partir de 1988 esse gasto se eleva consideravelmente e de forma permanente por causa da nova constituição promulgada no final daquele ano, que majorou as despesas públicas e as enrijeceu, aumentando a parcela de receita que o governo central deveria repassar aos estados e municípios sem o repasse de obrigações, o que exigia um aumento dos recursos para seu financiamento.

O consumo do governo salta de 13,45\% do PIB em 1988 para 19,29\% em 1990 se mantendo constante em aproximadamente $20 \%$ do PIB desde então. Em relação à rigidez destacamos a estabilidade do funcionalismo público, favorável à eficiência, mas que mantém fixos os gastos correntes com salários, e as despesas vinculadas que são relativamente fixas. O último grande aumento foi em 1995, primeiro ano do plano Real, que promoveu amplas reformas econômicas e administrativas. Esse aumento pode ser justificado pela defasagem dos preços e salários, que foram diversas vezes congelados e não acompanharam a escalada da inflação na década de 1980 e início dos 90 . Apesar de controlar melhor os gastos, tendo superávits primários desde 1997, o crescimento médio do produto no período 1995-2005 foi de $2,58 \%$, enquanto a despesa pública foi de $3,82 \%$.

Apesar de alguns economistas defenderem a tese de que esse aumento do consumo do governo foi exigido pela sociedade, que seria para suprir uma demanda reprimida por gastos públicos, principalmente sociais, ressaltamos que esse nível de dispêndio é muito diferente de países semelhantes ao Brasil e próximo ao gasto de nações desenvolvidas, que oferecem serviços públicos de excelente qualidade para sua população. Caso o gasto corrente não continue com crescimento maior que o produto, em alguns anos a relação gasto/PIB se reduziria, mas não é o que observamos nos últimos 15 anos.

\subsection{Comparações internacionais}

Apesar da baixa taxa de crescimento dos últimos anos, a economia brasileira apresentou desenvolvimento significativo, melhorando os indicadores sociais e aumentando a renda per capita. Não obstante, os indicadores brasileiros ainda não são satisfatórios e muitos deles ainda são piores que a maioria das economias semelhantes a nossa. O Brasil é classificado como país de renda média, ${ }^{2}$ sendo que seu PIB per capita (US\$ 3.000) é maior que a média de tais países (US\$ 2.274), mas menor que a média da América Latina (US\$ 3.576).

Em relação aos indicadores sociais, podemos comparar os dados brasileiros com os de outras economias de mercado que têm alcançado bons resultados econômicos e sociais. Observamos na Tabela 1 que entre as cinco economias de renda média (China, Brasil, Rússia, Chile e México) o Brasil é o que apresenta o pior desempenho, apesar dos avanços dos últimos anos, ainda apresenta um quadro social aquém dos demais países em desenvolvimento. O Chile é um país com território e população muito menores que os nossos, e também com um desenvolvimento político muito superior, o que poderia justificar seu melhor desempenho. Mas China e Rússia são países continentais, com uma curta história de economia de mercado e problemas políticos e sociais preocupantes. Uma observação deve ser feita, países como China e Índia podem não divulgar dados sociais confiáveis, principalmente os referentes a pobreza.

\footnotetext{
${ }^{2} \mathrm{O}$ Banco Mundial classifica seus países membros e as demais economias com mais de 30.000 habitantes em três grupos de acordo com o PIB per capita, sendo que em 2004 essa classificação foi a seguinte: Baixa renda: Até US\$ 826; Renda média: De US\$ 826 a US\$ 10.065; Renda alta: Acima de US\$ 10.065. Esta será a classificação utilizada nas comparações entre os países desta seção.
} 
Impactos de Longo Prazo de Reformas Fiscais sobre a Economia Brasileira

Tabela 1: Indicadores sociais - Países selecionados (2004) ${ }^{3}$

\begin{tabular}{lccccccc}
\hline & $\begin{array}{c}\text { PIB per } \\
\text { capita }\end{array}$ & $\begin{array}{c}\text { Taxa de } \\
\text { crescimento }\end{array}$ & IDH & $\begin{array}{c}\text { Mortalidade } \\
\text { infantil }\end{array}$ & Alfabetização & Gini & Pobreza \\
\hline Índia & 620 & 3,87 & 0,611 & 57,92 & 64,46 & 0,368 & 0,265 \\
China & 1500 & 8,10 & 0,768 & 25,28 & 92,63 & 0,469 & 0,072 \\
Brasil & 3000 & 0,82 & 0,792 & 30,66 & 89,11 & 0,570 & 0,297 \\
Rússia & 3400 & 4,03 & 0,797 & 16,96 & 99,48 & 0,405 & 0,193 \\
Chile & 5220 & 2,77 & 0,859 & 9,05 & 96,27 & 0,549 & 0,180 \\
México & 6790 & 3,00 & 0,821 & 20,91 & 91,00 & 0,461 & 0,154 \\
Coréia do Sul & 14000 & 4,00 & 0,912 & 7,18 & 97,90 & 0,342 & 0,150 \\
\hline
\end{tabular}

Fontes: Banco Mundial, PNUD, CIA, UNESCO.

Mas o governo brasileiro possui comportamento diverso dos países de renda média em relação às contas públicas, arrecada e gasta como os países desenvolvidos. No Gráfico 1 encontra-se a distribuição de densidade do consumo final das administrações públicas de 141 países para os quais o Banco Mundial possui informações para o ano de $2004 .{ }^{4}$ A média mundial é de $15,23 \%$ e vemos que o Brasil se encontra bem após a média junto de países como Alemanha e Itália. Uma observação deve ser feita, dos 63 países que compõe nossa amostra de "países de renda média" o consumo do governo brasileiro só é menor que 14 dessas economias, e dessas, somente sete possuem PIB per capita inferior ao do Brasil.

Enquanto a média de gasto corrente ${ }^{5}$ dos países de renda média é de $15 \%$ do PIB e o gasto dos países emergentes com os quais estamos comparando o Brasil é de 13\%, o Brasil apresenta consumo das administrações públicas de $19 \%$ do PIB, e esse valor tem se mantido constante na última década, como visto no tópico 2.2. Na Tabela 2 vemos que esse é o gasto dos países de renda alta, que oferecem serviços públicos muito superiores aos brasileiros, são economias não somente ricas, mas também desenvolvidas.

Observamos o mesmo comportamento em relação à arrecadação, ${ }^{6}$ onde a sociedade brasileira é taxada como as nações desenvolvidas. Mas isso é um fenômeno da última década. Em 1995 a arrecadação brasileira não era muito superior à média dos países de renda média $(26,9$ contra 23,3), mas em 2004 essa diferença passa de sete pontos.

Por fim, o gasto total, também elevado, só é menor que a média dos países europeus que compõe a área do Euro. Essa rubrica, além do consumo do governo, compreende os gastos com juros e benefícios sociais. Na Tabela 2 vemos que apesar da dívida brasileira não ser demasiadamente elevada e a propor-

\footnotetext{
${ }^{3}$ Definições e Fontes: PIB per capita em US\$ - Banco Mundial. Média da taxa de crescimento do PIB per capita (1995-2004) - Banco Mundial. Índice de Desenvolvimento Humano - PNUD - Programa das Nações Unidas para o Desenvolvimento. Taxa de mortalidade infantil em 1000 nascidos - CIA - The World FactBook - Central Intelligence Agency - USA. Taxa de alfabetização da população de 15 anos ou mais - UNESCO - Organização das Nações Unidas para a Educação. Gini: Índice de desigualdade - CIA. Pobreza: porcentagem da população com renda média abaixo de linha estabelecida no país - CIA.

${ }^{4}$ A definição do Banco Mundial de "Despesa de consumo final das administrações públicas" inclui todas as despesas públicas correntes para as compras de bens e serviços (incluindo as remunerações dos empregados). Esse valor é retirado das Contas Nacionais dos países.

${ }^{5}$ Consideramos "gastos correntes" somente o consumo final das administrações públicas, não inclui gastos com previdência e pagamentos de juros.

${ }^{6}$ O Banco Mundial considera como "Receitas" toda receita de impostos, contribuições sociais, e de outras receitas, tais como multas, taxas, rendas e rendimentos de propriedade ou de venda.
} 
Gráfico 1 - Distribuição do consumo final das administrações públicas como \% do PIB (2004)

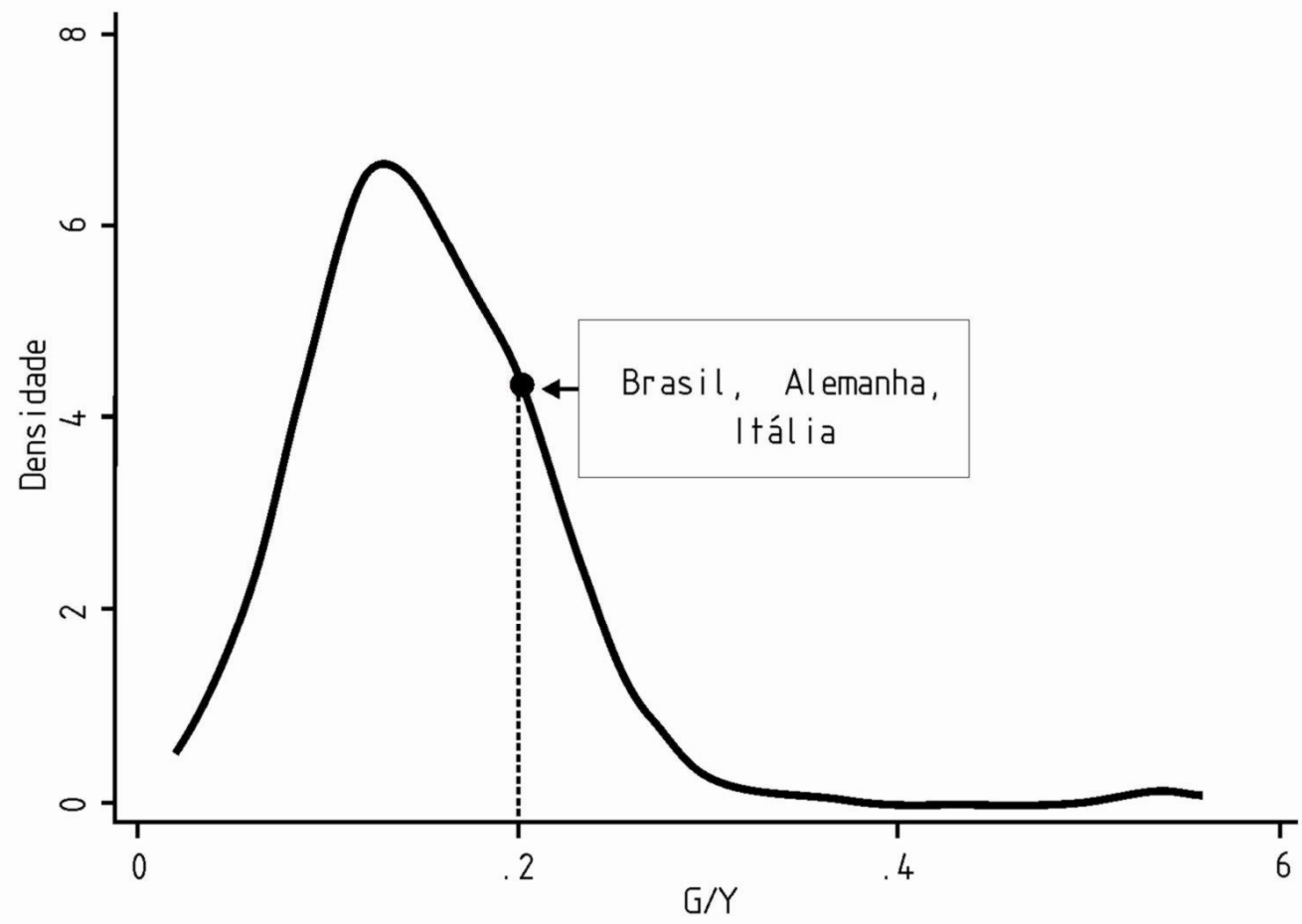

ção da população idosa não ser comparável a de países desenvolvidos, o gasto total do governo é até superior que o gasto dos países desenvolvidos.

\subsection{Exercício empírico}

Utilizando a hipótese de que o Estado deveria promover o bem-estar social, faremos um exercício empírico comparando o gasto do governo brasileiro com os demais países, buscando confirmar ou refutar a teoria de que o gasto público é demasiadamente elevado no Brasil, sendo esta estimação chamada "lei de Wagner", que teoriza que o gasto público é um bem superior que cresce com a elevação da renda de um país. Barro (1989) testa essa lei, regredindo diversos tipos de gastos públicos e encontra significância apenas para os gastos com educação e seguridade social. Em nosso exercício iremos regredir o consumo final das administrações públicas na renda e em outras variáveis de controle, de acordo com a equação (1):

$$
g / y=\alpha+\beta_{1}^{*} \ln y+\beta_{2}^{*} X^{\prime}
$$

onde $g / y$ é o gasto corrente do governo como porcentagem do PIB, $\ln (y)$ é o logaritmo neperiano do PIB per capita e $X$ é um vetor de variáveis de controle que acreditamos influenciar nos gastos do governo. As variáveis utilizadas no vetor $X$ são:

- Densidade: Densidade populacional, utilizando dados do Banco Mundial para 2004. Estimações de população (ou censos demográficos). Espera-se que o coeficiente dessa variável seja negativo, países 
Impactos de Longo Prazo de Reformas Fiscais sobre a Economia Brasileira

Tabela 2: Finanças públicas (\% do PIB) - 2004

\begin{tabular}{lccccc}
\hline & Receitas & Gastos & $\begin{array}{c}\text { Consumo } \\
\text { do Governo }\end{array}$ & $\begin{array}{c}\text { Dívida } \\
\text { Pública* }\end{array}$ & \% Idosos** \\
\hline Renda Baixa + & 21,8 & 21,6 & 13,1 & 86,4 & 3,5 \\
Renda Média + & 25,0 & 25,9 & 15,0 & 48,7 & 7,9 \\
Renda Alta + & 34,5 & 34,2 & 19,4 & 58,1 & 13,4 \\
América Latina & 21,2 & 21,2 & 14,0 & 58,9 & 5,9 \\
Área do Euro & 35,7 & 38,6 & 20,0 & 66,0 & 16,2 \\
Brasil & $32,7++$ & $36,6++$ & 19,0 & 52,0 & 6,0 \\
\hline
\end{tabular}

Fonte: WDI, Banco Mundial e CIA.

(*) Dívida Pública total como porcentagem do PIB. (**) Porcentagem da população com 65 anos ou mais.

(+) Calculado pelos autores com dados do WDI, Banco Mundial. (++) Receita Federal e Tesouro Nacional.

mais densos apresentem consumo público menor, ou seja, haja "efeito escala" no gasto do governo, um mesmo bem público (a justiça, por exemplo) seria utilizado por mais pessoas.

- Gini: Índice de Gini calculado por pesquisas locais entre 2000 e 2004. Fonte: Banco Mundial e CIA. ${ }^{7}$

- Pobreza: Porcentagem da população abaixo da linha de pobreza estabelecida por pesquisas locais entre 2000 e 2004. Fonte: CIA e Banco Mundial.

É esperada relação negativa entre essas duas variáveis e o consumo do governo, pois nações com alto nível de concentração de renda e elevada pobreza são em geral países subdesenvolvidos.

Outras variáveis foram testadas, como porcentagem de crianças na população, taxa de desemprego, índice de desenvolvimento humano (IDH) e dummies regionais, mas não se mostraram significativas e não contribuíram para melhorar o ajuste da regressão, e decidimos por não apresentar tais resultados. Essas variáveis seriam incluídas para tentar captar o efeito da necessidade de gastos na área social.

Uma segunda formulação da equação (1) seria regredir o gasto total, incluindo pagamentos de juros e da seguridade social, e acrescentar dois controles, a dívida pública e a porcentagem de idosos na população. Apresentamos os resultados nas colunas três e quatro da Tabela 3, juntamente com os resultados para a primeira formulação, e eles sugerem a confirmação da lei de Wagner, tanto para o consumo do governo quanto para o gasto total.

Em ambos os modelos, a renda per capita se mostrou significante a mais de 5\% de confiança, ou seja, economias com maiores rendas apresentam maior gasto público. A densidade populacional mostrou o sinal esperado, e apesar de ser altamente significante nas três primeiras regressões, possui elasticidade muito baixa, alterando muito pouco a determinação do nível de despesa pública. Pela primeira estimação, o consumo final do governo geral brasileiro deveria ser de aproximadamente $16 \%$ do PIB e não os atuais $19 \% .^{8}$

Ao inserir outros dois controles nesse modelo, as variáveis gini e pobreza, o modelo se torna globalmente melhor ajustado. A variável pobreza foi estatisticamente significativa e positiva. Mas isso

\footnotetext{
${ }^{7}$ Ver nota de rodapé 3 para definição das fontes.

${ }^{8}$ A média de 1995 a 2010 foi de 20\% do PIB. Em 2004 o gasto foi de 19\%, valor utilizado nesse exercício empírico.
} 
pode ser explicado por dois motivos: países pobres podem estar realizando maiores gastos sociais para reduzir a pobreza e/ou pelo fato dos países com maior nível de pobreza terem problemas políticos que aumentam o gasto, como ineficiências e corrupção. Já a variável gini não se mostrou significativa, apesar do sinal esperado (negativo), não podemos inferir sobre sua influência no dispêndio público. Por essa formulação, o consumo público deveria ser $18,36 \%$ do PIB, ou seja, para eliminar os problemas sociais, um maior gasto deve ser realizado, sendo essa a tese de muitos economistas para explicar o aumento da despesa pública nas últimas duas décadas no Brasil.

Por fim, as estimações do gasto total apresentam significância global maior que a primeira formulação, sendo a elasticidade da renda mais elevada. Países ricos apresentam consumo do governo maior que nações pobres, mas quanto maior a renda, maior o gasto total. E pelo modelo, essa diferença pode ser em parte explicada pela magnitude da dívida pública e pela porcentagem da população idosa, pois ambas as variáveis se mostraram significativas e com elevada elasticidade.

Tabela 3: Variável dependente: Despesa final das administrações públicas (colunas 1 e 2) e Despesa total do Governo (3 e 4)

\begin{tabular}{lcccc}
\hline & 1 & 2 & 3 & 4 \\
\hline Constante & 0,04 & 0,018 & $-0,101$ & $-0,117$ \\
lny & $-0,029$ & $-0,049$ & $-0,067$ & $-0,096$ \\
& $0,015^{*}$ & $0,022^{*}$ & $0,032^{*}$ & $0,035^{*}$ \\
densidade** & $-0,003$ & $-0,004$ & $-0,01$ & $-0,014$ \\
& $-0,002^{*}$ & $-0,002^{*}$ & $-0,004^{*}$ & $-0,004$ \\
Gini & 0 & 0 & $-0,005$ & $-0,005$ \\
& - & $-0,069$ & - & $-0,096$ \\
pobreza & - & $-0,074$ & - & $-0,138$ \\
& - & $0,092^{*}$ & - & 0,059 \\
dívida pública & - & $-0,042$ & - & $-0,076$ \\
& - & - & $0,107^{*}$ & $0,116^{*}$ \\
idosos & - & - & $-0,009$ & $-0,009$ \\
& - & - & $0,546^{*}$ & $0,669^{*}$ \\
$R^{2}$ & 0,155 & 0,227 & 0,565 & 0,62 \\
Obs. & 140 & 107 & 83 & 65 \\
Gasto Brasi ${ }^{* * *}$ & $15,99 \%$ & $18,36 \%$ & $24,26 \%$ & $22,19 \%$ \\
\hline
\end{tabular}

Erro padrão na segunda linha de cada variável.

(*) Coeficiente significativo a $10 \%$ ou mais.

$\left.{ }^{* *}\right)$ Valores multiplicados por 100.

${ }^{(* *)}$ Gasto público brasileiro como porcentagem do PIB estimado pelos modelos.

Este exercício demonstra que o consumo da administração pública brasileira, está acima dos padrões mundiais, sendo essa a primeira contribuição deste trabalho. Mas é possível que esse seja um nível de dispêndio necessário para suprir uma demanda reprimida durante várias décadas de investimentos nas 
áreas sociais. Em relação ao gasto total, apesar da dívida pública não ser demasiada e estar em trajetória de queda, alguns autores alegam que a dívida brasileira ainda não apresenta um bom perfil, com prazos curtos e taxas de juros elevadas, o que torna o endividamento brasileiro muito custoso para os cofres públicos.

O exercício não especifica qual o gasto com transferências a aposentados, mas os resultados demonstram que países com uma porcentagem maior de idosos na população apresentam um maior gasto do setor público. Nesse sentido, a porcentagem de idosos na população brasileira não justifica um elevado gasto com previdência, e consequentemente, um maior gasto total, mas esse assunto precisa ser tratado com mais cautela, analisando a estrutura do sistema previdenciário e sua sustentabilidade, o que não é o escopo deste estudo.

\section{O MODELO}

Para analisar os efeitos de alterações fiscais na economia brasileira empregaremos um modelo neoclássico com economia fechada, crescimento exógeno e população constante e, dessa forma, focaremos apenas nos efeitos da política fiscal. Essa caracterização da economia tem sido utilizada em estudos fiscais, como Ferreira e Araújo (1999) e Paes e Bugarin (2006a).

As famílias vivem infinitos períodos e maximizam uma função utilidade cuja cesta é composta de consumo e lazer. Algumas formulações adicionam parte do gasto público como componente da cesta de consumo (Ferreira e Nascimento, 2006), e seguiremos tal formulação, considerando que as famílias atribuem um peso ao bem público em sua cesta de consumo. Há um único bem na economia, produzido por um único setor produtivo, que utiliza três insumos: trabalho, capital privado e capital público.

O governo arrecada tributos sobre consumo, renda do trabalho e renda do capital e mantém o orçamento equilibrado a cada período. Apesar da dívida pública estar em 40.16\% do PIB (Banco Central, dezembro/2010) e a parcela de juros paga ser elevada, desconsideraremos superávits e títulos públicos, pois a dívida encontra-se em trajetória de queda e muitos trabalhos tem contemplado os dois grandes problemas dos gastos públicos: juros e previdência social. Neste trabalho focaremos nos gastos com investimento e consumo final das administrações públicas, consideramos os demais gastos como "outros", não especificando se são pagamento de juros, transferências as famílias ou outros gastos.

\subsection{Famílias}

As famílias são dotadas de capital inicial $\left(k_{0}>0\right)$ no período inicial e uma unidade de tempo produtivo em cada período, que podem empregar em trabalho ou lazer $\left(h_{t}+l_{t}=1\right)$. A família representativa maximiza uma função utilidade sujeita a uma restrição orçamentária, sendo que sua renda é composta por renda do capital e do trabalho (líquidas de impostos) e transferências do governo, e sua demanda se distribui entre consumo e investimento, portanto, sua renda a cada período será:

$$
\left(l+\tau_{c}\right) c_{t}+k_{t+1}=w_{t} h_{t}\left(1-\tau_{h t}\right)+k_{t}\left[r_{t}\left(1-\tau_{k t}\right)+(1-\delta)\right]+T
$$

sendo a função de acumulação de capital $k_{t+1}=i_{t}+(1-\delta) k_{t}$. A função utilidade será do tipo Cobb-Douglas, na forma logarítima:

$$
U\left(c_{0}, l_{0}, c_{1}, l_{1}, \cdots, c_{\infty}, l_{\infty}\right)=\sum_{0}^{\infty} \beta^{t}\left[\ln \left(c_{t}+\mu C g_{t}\right)+\theta \ln l_{t}\right]
$$

O parâmetro $(\beta)$ é a taxa subjetiva de desconto intertemporal, $0<\beta<1$, o parâmetro $\mu$ mede como o indivíduo representativo valoriza o consumo público em relação ao consumo privado e $(\theta)$ é o parâmetro que representa o peso do lazer na função utilidade. Como as famílias vivem infinitos períodos, estas desejam maximizar o valor presente dos fluxos de utilidade de todos os períodos, portanto, o problema da família representativa será maximizar a função em (3) sujeita a restrição em (2). 


\subsection{Firmas}

Seguindo Ferreira e Nascimento (2006), o modelo adotado neste trabalho tem um único setor produtivo, que utiliza como insumo capital privado, mão de obra (não haverá diferenciação entre trabalho qualificado e não qualificado) e o bem público. Este não é utilizado por uma única firma, pois consideramos que não há congestionamento no uso do mesmo, logo, esse fator entra de forma agregada na função de produção da firma representativa. A produção do único bem da economia pode ter três destinos, consumo, investimento ou ser gasto do governo.

Esta formulação implica que o capital público é essencial à produção, não sendo possível que o setor privado o oferte, nem tão pouco substituí-lo pelo capital privado. Barro (1990) e Aschauer (1989) utilizam essa hipótese, baseados em constatações empíricas em relação à importância do capital público (infraestrutura) para a produção privada. O problema que a firma representativa enfrenta é estático e da forma:

$$
\max _{K_{t}, H_{t}} A_{t} K_{t}^{\alpha} H_{t}^{1-\alpha} K g_{t}^{\gamma}-w_{t} H_{t}-r_{t} K_{t}
$$

A produção exibe retornos constantes de escala nos fatores capital e trabalho, e o capital público traz externalidade positiva à produção, medida pelo parâmetro $(\gamma)$. A economia apresenta crescimento exógeno através da variável que representa a tecnologia $\left(A_{t}\right)$, que cresce a uma taxa constante, $A_{t+1}=A_{t}(1+\varphi)$, essa é a principal hipótese adotada no modelo que garante o crescimento de estado estacionário da economia.

\subsection{Governo}

A receita do governo ( $G_{t}$ na equação 5$)$ é oriunda da tributação sobre as rendas do capital $\left(r_{t} k_{t} \tau_{h t}\right)$ e do trabalho $\left(w_{t} h_{t} \tau_{k t}\right)$ e sobre o consumo $\left(c_{t} \tau_{c t}\right)$. Os gastos públicos se dividem em investimento (em infraestrutura), gastos correntes e outros gastos (transferências, juros e outras despesas) sendo que o governo destina uma parcela fixa da arrecadação para cada rubrica (equação 6). Sem perda de generalidade, o orçamento público estará em equilíbrio em todos os períodos, não havendo possibilidade de endividamento. $\mathrm{O}$ capital público tem uma função de acumulação similar ao capital privado (equação 7).

$$
\begin{gathered}
G_{t}=w_{t} h_{t} \tau_{h t}+r_{t} k_{t} \tau_{k t}+c_{t} \tau_{c t} \\
I g_{t}=\lambda G_{t}, C g_{t}=\eta G_{t} \text { e } T_{t}=(1-\lambda-\eta) G_{t} \\
K g_{t+1}=I g_{t}+\left(1-\delta_{g}\right) K g_{t}
\end{gathered}
$$

\subsection{Equilíbrio Competitivo}

As hipóteses adotadas na construção do modelo garantem a convergência para um único estado estacionário. As equações que descrevem a trajetória até o equilíbrio $(8,9$ e 10) são encontradas a partir da solução do problema das famílias (maximização de (3) sujeita a restrição em (2)), onde $r_{t}$ e $w_{t}$ resultam da resolução do problema das firmas (4) e das restrições (5) e (10):

$$
\begin{gathered}
c_{t+1}=\beta\left[\left(1-\tau_{k}\right) r_{t+1}+(1-\delta)\right] c_{t} \\
\frac{\theta c_{t}}{\left(1-h_{t}\right)}=\frac{\left(1-\tau_{h t}\right)}{\left(1+\tau_{c t}\right)} w_{t}
\end{gathered}
$$




$$
C_{t}+C g_{t}+K_{t+1}+K g_{t+1}=K_{t}^{\alpha} H_{t}^{I-\alpha} K g_{t}^{\gamma}+(1-\delta) K_{t}+\left(1-\delta_{g}\right) K g_{t}
$$

Uma ressalva deve ser feita, as equações acima precisam ser transformadas por unidade de eficiência, uma vez que há crescimento exógeno na economia.

\subsection{Equilíbrio Centralizado}

Utilizaremos a figura de um Planejador Central que irá maximizar a utilidade das famílias (3) sujeita a restrição de recurso da economia (10), escolhendo o nível ótimo de capital, trabalho, consumo e capital público. o planejador considera $\mu=1$, ou seja, valora consumo privado e consumo público da mesma forma, e determina qual é o consumo ótimo da economia. A existência de um planejador central é irrealista, mas necessária para efeito de comparação do primeiro melhor (alcançado por uma economia sem impostos distorcivos) e o segundo melhor (a economia real). A partir dessa formulação encontraremos qual o gasto ótimo em capital público.

\subsection{Medidas de Bem-Estar}

Para calcular a variação no Bem-Estar das famílias dado uma alteração na política fiscal, será utilizada a metodologia de Ferreira e Araújo (1999) e Paes e Bugarin (2006b), que calculam a variação compensada no consumo, ou seja, quanto deveria ser dado às famílias em termos de consumo para que elas fossem indiferentes entre os dois sistemas fiscais. O que se busca é um $\triangle$ que torne a equação (11) verdadeira:

$$
\ln \left(c_{s s}+\mu C g_{s s}\right)+\theta \ln \left(1-h_{s s}\right)=\ln \left[c_{R}(1+\triangle)+\mu C g_{R}\right]+\theta \ln \left(1-h_{R}\right)
$$

onde as variáveis com subscrito (ss) são de estado estacionário original (situação em 2010) e com subscrito $(R)$ são os valores de equilíbrio dado a reforma fiscal. De forma agregada, a variação de bemestar é estimada como a porcentagem do PIB necessária para que o bem-estar da população fosse o mesmo de antes da reforma:

$$
\triangle \text { Bem-Estar }=\left(c_{R}^{*} \triangle\right) / Y_{R}
$$

Dessa forma, estimaremos a equação (12) para avaliar o impacto das reformas fiscais (simulações) sobre o bem-estar da população.

\subsection{Calibragem do Modelo}

Para analisar os efeitos econômicos de alterações na estrutura atual do governo, será adotada a metodologia utilizada por Ferreira e Araújo (1999) e Ferreira e Nascimento (2006) entre outros, onde os parâmetros do modelo são calibrados com dados reais da economia brasileira. Para analisar os efeitos de tais mudanças, serão realizados exercícios de simulação, supondo que a economia estaria em equilíbrio estacionário em 2010.

O gasto público brasileiro é dividido entre consumo final, investimentos e outros gastos. Iremos considerar "outros gastos" o gasto que não for consumo ou investimento, que compreende em grande parte transferências (inclusive a previdência) e o pagamento de juros.

\subsubsection{Calibragem dos parâmetros do modelo}

Primeiramente buscaremos valores para os parâmetros estruturais da economia que aproximem o modelo da realidade brasileira em 2010, para depois calcularmos as alíquotas "efetivas" que representarão o sistema tributário. 
O modelo apresenta crescimento exógeno através do fator produtivo $\left(A_{t}\right)$, que cresce à taxa $(\varphi)$, mas a economia cresce à taxa $(1+\psi)=(1+\varphi)^{1 /(1-\alpha-\gamma)}$, por causa do fator produtivo capital público na função de produção. Utilizaremos a taxa de crescimento da economia para transformar as três equações que descrevem a trajetória até o equilíbrio estacionário. Calibramos $(1+\psi)$ em 1,02\%, taxa média de crescimento do PIB per capita no período 1995-2010. Esse é um período muito curto para mensurar uma taxa média de crescimento, mas optamos por tal valor, pois o crescimento da renda brasileira é baixo desde a década de 1980, e se utilizarmos um período longo, uma média de 30 anos, por exemplo, estaremos utilizando as taxas de crescimento do "milagre econômico", e essa é uma realidade muito diferente de hoje e dos demais parâmetros do modelo.

A taxa de depreciação média do capital pode ser obtida a partir do estado estacionário de sua função de acumulação, dada por $K_{t+1}=I_{t}+(1-\delta) K_{t}$, transformando-a em unidade de eficiência $(\delta=$ $I / K-\psi)$. Estimativas para esses valores agregados são de difícil obtenção, mas podemos facilmente encontrá-los como proporção do PIB. A razão $(I / Y)$ pode ser obtida das contas nacionais, e no período 1995-2010 essa rubrica variou entre 0.15 e 0.19 , sendo que adotaremos no trabalho a média desse período, 0.17

Já a razão $K / Y$ não é tão simples, pois é necessário mensurar todo o estoque de capital da economia. Alguns trabalhos estimam essa razão para a economia brasileira, como Feu (2001), Silva Filho (2001), Morandi e Reis (2005) e esses valores oscilam entre 2.5 e 3.5. Seguiremos Paes e Bugarin (2006a), que baseados no trabalho de Morandi e Reis (2005) calibram essa razão em 3.2. Com esses valores, calibraremos a taxa média de depreciação em $\delta=0.0345$, usando essa taxa também para o capital público. Ferreira e Nascimento (2006) utilizam $\delta=0.0656$ para 1999 e Paes e Bugarin (2006b) calibram $\delta=0.0554$ para 2002 .

O parâmetro tecnológico $(\alpha)$ representa a participação do capital no produto. Das condições de primeira ordem do problema das firmas, temos que: $w=(1-\alpha)^{*}(K / H)^{\alpha} * K g^{\gamma}$, reescrevendo essa equação temos que $\alpha=1-\frac{H^{*} w}{Y}$.

Este parâmetro geralmente é estimado entre 0.3 e 0.5, Ferreira e Nascimento (2006) incluindo títulos públicos em seu modelo, calibram a taxa de juros num valor menor e encontram $\alpha=0.3686$, já Paes e Bugarin (2006a) calculam este parâmetro através da expressão acima (produto marginal do trabalho), e utilizando dados da POF (2002/03) para calibrar os valores referentes à participação da massa de salários na renda, encontram $\alpha=0.4266$. Utilizaremos este último valor.

A taxa de juros real dessa economia representa somente o aluguel do capital privado, uma vez que o modelo não contempla a existência de títulos e o capital público não possui remuneração, portanto, $r=\frac{\alpha}{K / Y}$, o que resulta no valor de $14,95 \%$.

O parâmetro tecnológico $(\gamma)$ representa o efeito do capital público sobre a produção privada. Diversos trabalhos empíricos buscam estimar este efeito, principalmente através da elasticidade infraestrutura/PIB.

Aschauer (1989) utilizando uma função Cobb-Douglas e dados anuais da economia Americana para o período 1949-85 encontra valores elevados para tal parâmetro, entre 0.36 e 0.49 , mas apesar de demonstrar a importância do capital público, seus resultados podem ter sido superestimados por causa da metodologia utilizada (OLS). Para o Brasil, Ferreira e Araújo (1999) encontram a elasticidade infraestrutura/Produto de Longo Prazo em torno de 0.4, mas Ferreira e Nascimento (2006) preferem utilizar $\gamma=0.09$, valor encontrado por apud Ferreira (1993) para a economia Americana, e justificam tal escolha conservadora, pois todos esses resultados empíricos não utilizam as mesmas hipóteses do modelo teórico, além da superestimação de tais valores devido a problemas econométricos como em Aschauer (1989). Seguiremos Ferreira e Nascimento (2006) e adotaremos posição conservadora, utilizando $\gamma=0.09 .^{9}$

\footnotetext{
${ }^{9}$ Para uma discussão mais detalhada sobre estudos empíricos para o parâmetro tecnológico $(\gamma)$ ver Ferreira e Nascimento (2006).
} 
O fator de desconto intertemporal da utilidade das famílias $(\beta)$ pode ser calculado através da equação (8) no estado estacionário $\beta=\frac{\psi}{\left(1-\tau_{k t}\right) r+(1-\delta)}$, que resultará em $0,9306 .^{10}$

Encontramos o parâmetro da utilidade $(\theta)$ isolando-o na equação (9) e substituindo todos os valores de estado estacionário. O fator trabalho será calibrado com seu valor de 2009 , ao invés de ser calculado dentro do modelo. Pelos dados da PNAD (2009), as pessoas dedicavam $23,80 \%$ de seu tempo no trabalho principal ou secundário, o que representa pouco mais de 40 horas semanais (na média). Portanto, $h^{S S}=0.2380$ e $\theta=1,9365$.

Ferreira e Nascimento (2006) calibram o parâmetro $\mu$ (peso do consumo público na utilidade das famílias) em 0.5 , e realizam análise de sensibilidade para $\mu=1$ (mesma valoração do consumo privado e público, assim como no caso do planejador central) e $\mu=0$ (o consumo público seria puro desperdício), apoiando tal escolha em trabalho empírico de Evans e Karras (1996), que estimam $\mu=1,14$ via GMM e as três alternativas $\mu=0,0,5$ ou 1 não seriam rejeitado por testes de hipóteses.

\subsubsection{Calibragem da política fiscal}

No modelo, a arrecadação do governo se dá através de três tipos de imposto: sobre o consumo, sobre a renda do capital e sobre a renda do trabalho, e distribui seus gastos em investimento em infraestrutura, que irá se tornar o capital público utilizado na produção privada, gastos correntes, que não afetam diretamente as escolhas dos agentes, mas afetam a utilidade das famílias, e transferências, que serão utilizadas para equilibrar o orçamento público. Dividindo a equação (5) pelo produto, teremos a arrecadação em porcentagem do PIB, $G_{t} / Y=\left(w_{t} h_{t} \tau_{h t}\right) / Y+\left(r_{t} k_{t} \tau_{k t}\right) / Y+\left(c_{t} \tau_{c t}\right) / Y$, e podemos calcular as três alíquotas utilizando dados da Recita Federal e alocando todos os tributos brasileiros em uma das três rubricas existentes no modelo. ${ }^{11}$

Em 2010 a arrecadação do governo geral foi de $33,56 \%$ do PIB, ${ }^{12}$ sendo que a tributação sobre o consumo representou $15,70 \%$ do PIB. Podemos obter a razão consumo/produto das contas nacionais (IBGE), assim como a razão investimento/produto, e iremos considerar a média de 1995-2010 para essas duas variáveis, pois essas razões não se alteram rapidamente e dessa forma captamos melhor a realidade brasileira. Consideramos o consumo agregado das famílias e da administração pública, já que o governo também paga impostos sobre os bens e serviços que adquire do setor privado, portanto, $C / Y=83 \%$, resultando em uma alíquota $\tau_{c}=19,02 \%$. Já a arrecadação sobre a renda do capital representou no ano considerado, 5,40\% do PIB, e usando os valores da taxa de juros e razão capital/produto já mencionados, encontramos a alíquota sobre o capital $\left(\tau_{k}=12,67 \%\right)$. Por fim, a arrecadação sobre a renda do trabalho foi de $12,45 \%$ do PIB, mas não é possível calcular a alíquota diretamente da equação (5), pois os dados da massa de salários $\left(w_{t}^{*} h_{t}\right)$ é de difícil obtenção. Precisaremos adicionalmente da condição de ótimo das firmas, onde $w_{t}=(1-\alpha)^{*} Y / H$, de onde calculamos a alíquota sobre o trabalho $\left(\tau_{h}=21,71 \%\right)$.

Em relação aos gastos, iniciaremos a análise considerando a média do período $1995-2006^{13}$ para a formação bruta de capital fixo das administrações públicas, onde foi gasto apenas 1,89\% do PIB e $20 \%$ do PIB em consumo final das administrações públicas (média 1995-2010) (Contas Nacionais, IBGE).

Os demais gastos (no nosso modelo, transferências, pagamentos de juros e outras despesas) não apresentam valores consensuais entre os diversos órgãos que fazem sua medição (Receita Federal, o

\footnotetext{
${ }^{10}$ Primeiramente calculamos a alíquota sobre o capital para depois estimar o parâmetro $\beta$, entretanto o apresentamos juntamente com os demais parâmetros estruturais. $O$ cálculo da alíquota encontra-se na próxima subseção.

${ }^{11}$ Consideramos tributos sobre o consumo: ICMS, COFINS, PIS, IPI, ISS, IE, CIDE, IOF, Outros tributos estaduais, Taxas estaduais, Taxas municipais, Taxas Federais, FUNDAF, Outros tributos municipais, Demais contribuições econômicas. Tributação sobre o capital: IRPJ, CSLL, IPVA, IPTU, ITBI, ITCD, ITR. Tributação sobre o trabalho: Contribuição para a previdência social, IRPF, FGTS, Previdência estadual, Contribuição seguridade do servidor público, Salário educação, Sistema S, Previdência municipal, PASEP.

${ }^{12}$ Fonte: "Carga Tributária no Brasil - 2010". Estudos tributários da Receita Federal.

${ }^{13} \mathrm{~A}$ última informação sobre essa rubrica é de 2006.
} 
Tesouro Nacional, o IBGE e o BNDES). Adotando a hipótese de orçamento equilibrado e calibrando o modelo com os dados acima, esse gasto foi de $11,46 \%$ do PIB.

Quadro 1 - Resumo dos parâmetros estruturais e fiscais da economia

\begin{tabular}{l|l|c|l}
\hline$(1+\psi)$ & Taxa de crescimento da economia & 1,02 & média 95-10 \\
$\delta$ & Taxa de depreciação & 0,03 & $\delta=I / K-\Psi$ \\
$\alpha$ & Participação do capital no produto & 0,43 & Paes, 2006 \\
$\mu$ & Peso do consumo do governo na utilidade & 0,5 & Ferreira, 2006 \\
$r$ & Taxa de juros & 0,15 & $r=\alpha / K / Y$ \\
$\gamma$ & Externalidade capital público & 0,09 & Ferreira, 2006 \\
$\beta$ & Taxa de desconto subjetiva intertemporal & 0,93 & equação 8 \\
$h$ & Horas trabalhadas & 0,24 & PNAD, 2009 \\
$\theta$ & Peso do lazer na utilidade & 1,94 & equação 9 \\
$\tau_{c}$ & Alíquota sobre o consumo & 0,19 & equação 5 \\
$\tau_{h}$ & Alíquota sobre a renda do trabalho & 0,22 & equação 5 \\
$\tau_{k}$ & Alíquota sobre a renda do capital & 0,13 & equação 5 \\
$C g$ & Consumo final das administrações públicas & 0,2 & média 95-10 \\
$I g$ & Formação bruta de capital fixo adm. Direta & 0,02 & média 95-10 \\
Outros & Transferências, juros, outros gastos & 0,11 & Residual \\
\hline
\end{tabular}

\section{RESULTADOS}

\subsection{Planejador central: Investimento público ótimo}

Primeiramente vamos analisar o resultado de equilíbrio centralizado, onde o planejador social escolhe de forma ótima o capital privado, capital público e as horas trabalhadas, de forma a maximizar a utilidade da família representativa. Nessa economia não há tributação, portanto o produto e o consumo serão máximos, e a variação de bem-estar será maior que todas as simulações. Esse resultado é chamado pela teoria econômica de "primeiro melhor". Esta é uma situação muito irrealista, mas o que é importante nesse exercício é calcular qual deveria ser o gasto ótimo em investimento público, que será utilizado nas simulações. Essa é a segunda contribuição deste trabalho, calcular a partir de um modelo hipotético, qual deveria ser a taxa de investimento do setor público.

Nesse cenário o capital público é $189 \%$ maior que o atual, sendo que a razão investimento público/PIB se elevaria dos atuais 1,89\% para 3,75\%, valor próximo da média da década de $1970(3,71 \%)$ e um pouco inferior a taxa utilizada por Ferreira e Nascimento (2006) em suas simulações (4,00\%). Como não há impostos distorcivos, o setor privado também aumentaria sua taxa de investimento e a economia passaria a poupar $22 \%$ do PIB ao invés dos atuais $17 \%$. O estoque de capital privado sofreria um grande aumento $(66 \%)$ e a taxa de juros cairia de $15 \%$ para $13 \%$, demonstrando que a taxa de juros brasileira não está muito longe de seu equilíbrio, dado a atual estrutura da economia.

Já a oferta de trabalho se elevaria muito bem menos que o capital (11\%), aumentando a razão capital/trabalho, a produtividade dos trabalhadores e consequentemente haveria elevação significativa dos salários (31\%). Uma observação deve ser feita, como essa simulação elimina os tributos distorcivos e aumenta muito o capital da economia, esse será o maior aumento que observamos nas horas trabalhadas. Esses resultados corroboram a hipótese de Chamley (1986) de que a taxação sobre a renda do 
capital deveria ser nula, aumentando assim o estoque de capital, a produtividade do trabalho, a renda e o bem estar da população. Por fim, a razão consumo/produto diminuiria para $78 \%$ (ante $83 \%$ atuais), sendo esse consumo a soma do consumo público e do consumo privado, pois ambos são valorados pelo planejador com a mesma importância.

Esses resultados são ideais, numa economia sem tributos, com oferta ótima de todos os bens necessários para a sociedade, inclusive os bens públicos, saúde, educação, saneamento, segurança, justiça, infraestrutura, entre outros, com um planejador central "benevolente" cuidando para que a economia esteja sempre otimizando o bem estar. Portanto, são resultados para serem observados com cautela. Na verdade o que tiramos desse exercício é qual deveria ser o gasto em investimento do setor público, como dito anteriormente.

\section{Simulações}

Em nosso modelo, o Estado interfere de duas formas na economia. Por um lado, o investimento público é um insumo produtivo e o aumento do gasto com esse fator irá elevar o produto. Por outro lado, a receita do governo é obtida através de tributos que modificam a alocação dos fatores. 0 imposto sobre o capital diminui a taxa de investimento privado e os impostos sobre o trabalho e consumo alteram as decisões de oferta de mão-de-obra das famílias, bem como a divisão do tempo produtivo entre consumo e lazer feita pelas mesmas. O consumo do governo não afeta diretamente a produção da economia, mas interfere no bem-estar, portanto, redução do consumo do governo reduz a utilidade da família representativa e consequentemente o bem estar. Mas se essa diminuição vier acompanhada de uma redução da tributação, seu efeito será favorável à atividade econômica, podendo ter um resultado final positivo. A partir dos resultados encontrados em 2.4 e 4.1 Iremos proceder quatro simulações:

1. Aumento do investimento público financiado pela redução do consumo público;

2. Aumento do investimento público financiado pela redução de "outros gastos";

3. Aumento do investimento público financiado por aumento de tributação;

4. Mesma razão investimento público/PIB, redução do consumo e outros gastos, redução proporcional da carga tributaria.

\subsection{Resultados macroeconômicos}

Iniciamos a análise pela quarta simulação, pois ela difere significativamente das três primeiras. Essa simulação analisa a redução da carga tributária acompanhando a queda do consumo do governo para o nível encontrado no exercício do tópico 2.4. A redução na alíquota sobre os ganhos do capital elevam a poupança privada, aumentando o estoque de capital de equilíbrio em $4 \%$. 0 aumento da poupança privada proporciona uma leve queda na taxa de juros de equilíbrio (1,50\%). Já a redução nas alíquotas do consumo e trabalho aumenta ligeiramente as horas de trabalho (1\%). Aliás, não há grandes alterações na oferta de trabalho nas simulações, primeiro porque não há mudanças significativas nas alíquotas que favoreçam maior oferta de trabalho, segundo porque a análise é feita de forma agregada, e as horas ofertadas já são em média elevadas. 0 pequeno aumento dos dois fatores produtivos proporciona elevação de apenas $2,66 \%$ do produto, mesmo valor de elevação do capital público (que é uma parcela fixa do produto).

Em termos de bem-estar, o consumo privado e os salários praticamente não sofrem alteração, e apesar da redução do consumo do governo, que reduziria a utilidade das famílias, o bem-estar se eleva em $2 \%$. Resumindo, em termos agregados, a simples redução do consumo público e queda proporcional da carga tributária não traz grandes ganhos à produção e ao bem-estar, sendo necessário ainda analisar a situação dos cofres públicos com essa reforma. Mas como o consumo público e a carga tributária são 
muito elevados, esse tipo de reforma poderia ser melhor analisada em nível microeconômico, analisando a queda de componentes específicos do consumo do governo e alterações microeconômicas de reformas tributárias. A Tabela 4 apresenta um resumo dos resultados de produção e bem-estar das simulações.

Tabela 4: Resultados macroeconômicos de longo prazo

\begin{tabular}{lccccc}
\hline & $\begin{array}{c}\text { Planejador } \\
\text { Central }\end{array}$ & Simulação 1 & Simulação 2 & Simulação 3 & Simulação 4 \\
\hline Invest. Privado (\% do PIB) & 17,79 & 15,54 & 15,54 & 15,39 & 15,78 \\
Invest. Público (\% do PIB) & 3,75 & 3,75 & 3,75 & 3,75 & 1,89 \\
\hline \multicolumn{5}{c}{ Variação em relação a 2010 do: } \\
\hline Investimento privado & 66,49 & 13,09 & 16,83 & 11,53 & 4,22 \\
Investimento público & 189,35 & 125,06 & 132,5 & 124,1 & 2,66 \\
Juros & $-12,67$ & 0 & 0 & 0,97 & $-1,5$ \\
Produto Interno Bruto & 45,39 & 13,09 & 16,83 & 12,61 & 2,66 \\
Consumo privado & 38,14 & 13,73 & 13,33 & 9,5 & 1,09 \\
Horas trabalhadas & 11,26 & $-0,43$ & 2,34 & 0 & 1,09 \\
Salários & 30,68 & 13,58 & 14,16 & 12,69 & 1,55 \\
Razão Capital/Trabalho & 49,63 & 13,58 & 14,16 & 11,61 & 3,1 \\
\hline BEM-ESTAR & 25,03 & 6,82 & 6,58 & 5,51 & 2 \\
\hline
\end{tabular}

Fonte: Elaboração própria.

Nas três primeiras simulações, a razão investimento público/PIB quase dobra e o investimento público se eleva entre 124 e $132 \%$. Obviamente essa não seria uma mudança imediata, esses são resultados alcançados no longo prazo. Mas o governo precisaria aumentar sua taxa de investimento para 3,75\% do PIB desde o primeiro período da mudança. O investimento privado como proporção do PIB é baixo no Brasil, 15,54\% (média 1995-2010), e as simulações aqui realizadas não alteram essa situação, pois não alteram os incentivos (alíquotas efetivas sobre o rendimento de capital), inclusive a terceira simulação que eleva as alíquotas resulta em um menor aumento do capital. Embora não haja grande alteração na taxa de poupança da economia, esse grande aumento de capital público torna o capital privado mais produtivo (por melhorias na infraestrutura, por exemplo), elevando o estoque de capital de equilíbrio entre 11 e $16 \%$.

O agente representativo leva em consideração todo o sistema fiscal na decisão de oferta de trabalho e não somente as alíquotas efetivas, a divisão do orçamento público em consumo, investimento e transferências também afeta essa decisão. Tudo mais constante, o aumento da parcela do PIB destinado ao investimento reduz o consumo privado (como proporção do PIB), fazendo com que a família aumente sua oferta de trabalho pra compensar a perda de consumo, e esse efeito existe nas três simulações. Mas a forma de financiamento pode reforçar ou anular esse efeito. Na simulação 1 , a redução da parcela do PIB destinada ao consumo público permite que aumente o consumo privado, e esse efeito é maior que o impacto do aumento do investimento público, provocando redução das horas de trabalho. Já na simulação dois, a redução das transferências diminui a renda disponível, reforçando o efeito de elevação de oferta de trabalho. Por fim, a simulação três, a queda na tributação produz efeito negativo sobre a oferta de trabalho, que se anula com o primeiro efeito, não alterando as horas.

Mas essas alterações são muito pequenas e a razão capital/trabalho se eleva, pois a oferta de trabalho é relativamente inelástica e não sofre grande alteração e o estoque de capital aumenta considera- 
velmente, majorando a taxa de salários. Dessa forma, apesar da elevação do estoque de capital, o fator trabalho aumenta sua parcela na renda, e não há alteração da taxa de juros de equilíbrio.

O bem estar aumenta com as reformas fiscais, sendo que a maior elevação (7\%) ocorre na primeira simulação, pois é neste cenário que encontramos o maior nível de consumo. Apesar do consumo público ter reduzido para financiar o aumento de investimento, e aquele ser parte componente utilidade individual, a redução das horas de trabalho (aumento das horas de lazer) e aumento do consumo privado compensam essa perda de utilidade e a variação de bem-estar é maior que as outras duas simulações.

Ao considerar o capital público indispensável na produção e não fornecido pelo setor privado, fazse necessário o aumento do dispêndio nesse tipo de investimento. Mesmo que o governo não retorne ao patamar da década de 1970 é necessário que alguém assuma esse papel, e o setor privado só o fará se o governo for o impulsionador, com redução de tributos, segurança nos contratos, liberação de recursos como os destinados ao PAC (Programa de aceleração do crescimento). As simulações sugerem que a melhor forma de financiamento desse aumento de investimento seria via realocação dos gastos públicos, e não por aumento na tributação, pois o efeito negativo do aumento das alíquotas reduz o efeito positivo do aumento de investimento, mas os resultados ainda são favoráveis.

\subsection{Transição para novo equilíbrio}

Para calcular o valor de cada variável durante a trajetória para o novo equilíbrio, foi utilizado um método quase-Newton de resolução de sistemas de equação não lineares (método de Broyden), e os resultados podem ser vistos nas figuras 1 e 2 . Os resultados da transição são apresentados como a variação de cada um dos agregados macroeconômicos (capital, horas de trabalho, consumo privado e bem-estar) em relação ao período inicial, do momento da reforma fiscal a 100 períodos à frente, dessa forma podemos visualizar o impacto da reforma desde o primeiro período. Ressaltamos que essa não é a melhor alternativa para análises de curto prazo, pois não há alterações de preços, a demanda agregada precisa se reajustar sem pressões inflacionárias.

Observamos que a primeira simulação apresenta os melhores resultados, não só no estado estacionário, mas também na transição. A redução do consumo do governo proporciona aumento do consumo privado desde o primeiro período e possibilita redução das horas de trabalho, e a combinação desses três impactos é positiva para o bem-estar, sendo que este aumenta desde o primeiro período. Somente o capital privado que cai inicialmente, pelo grande aumento da demanda por investimento público, e como já dito, não há pressões inflacionárias no modelo, e a demanda agregada precisa se ajustar.

Já em relação às simulações 2 e 3 , a mudança radical na composição do gasto público e na taxa de investimento da economia modifica a demanda agregada, reduzindo nos primeiros períodos o capital privado e o consumo, e consequentemente, o bem estar. Isso ocorre porque na simulação 2 o financiamento do aumento de investimento público é feito por redução nas transferências, que reduz a renda disponível das famílias, e na terceira simulação há aumento de tributação. Logo, no curto prazo a família precisa reduzir consumo privado. Mas o efeito positivo do maior investimento público logo é absorvido pela economia, aumentando a produtividade do capital privado, aumentando o produto, consumo e bem-estar. Mas essa queda de bem-estar inicial deve ser considerada na análise, pois a sociedade precisa fazer um "sacrifício" inicial para alcançar os benefícios de longo prazo. Cabe ressaltar que nas três simulações a mudança da taxa de investimento é muito expressiva, fazendo com que a economia demore muitos períodos para voltar a um equilíbrio de longo prazo.

Por fim, na simulação 4 a redução do consumo do governo e da alíquota sobre o consumo proporcionam elevação do consumo privado desde o primeiro período, aumentando o bem estar desde o início, apesar do impacto negativo dos outros dois componentes da cesta de consumo (redução do consumo público e aumento das horas de trabalho). A economia levaria apenas 20 períodos para se estabilizar, e os ganhos, apesar de sempre crescentes, são muito pequenos, como já dito anteriormente. 
Figura 1: Resultados econômicos da transição das simulações 1 e 2
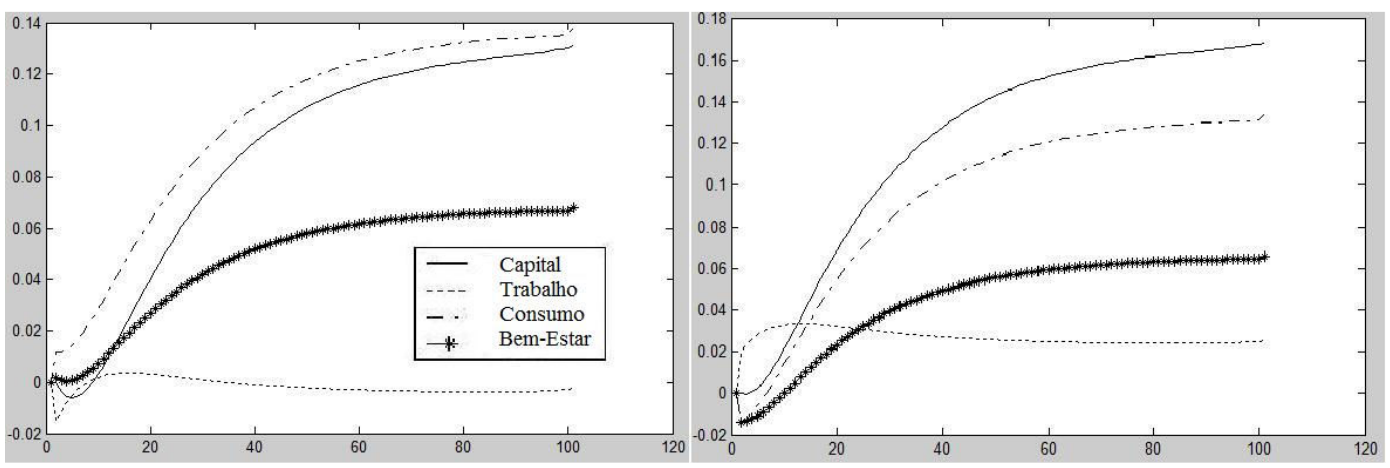

Figura 2: Figura 2 - Resultados econômicos da transição das simulações 3 e 4
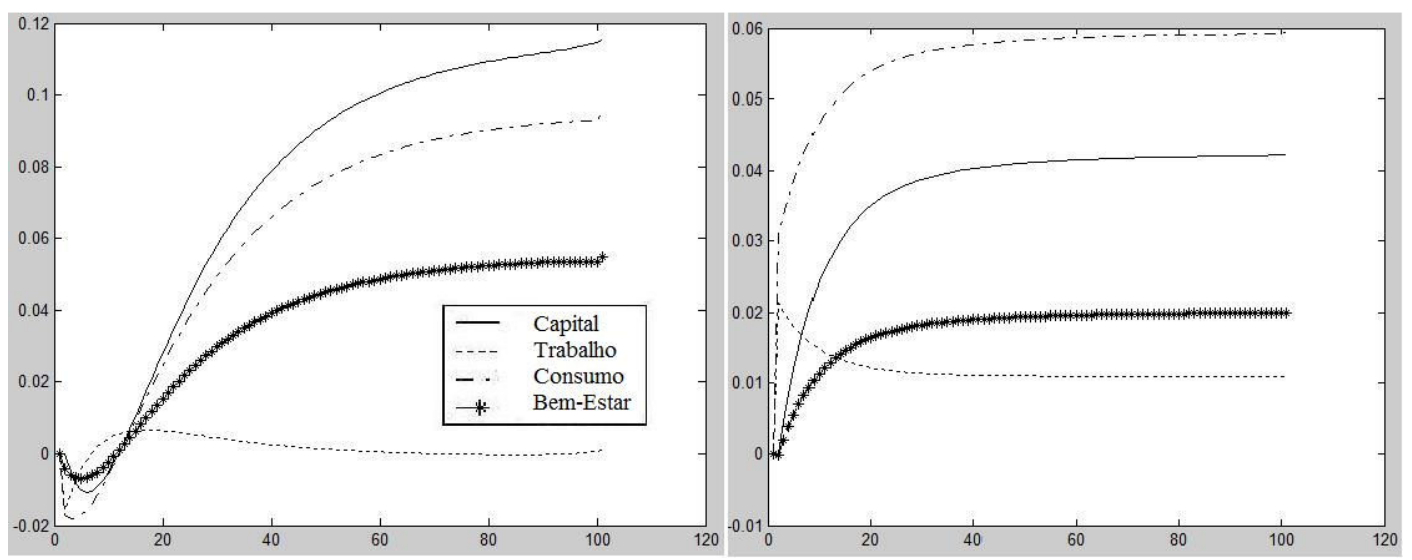

\subsection{Resultados fiscais}

O escopo desse trabalho é analisar as alterações ocorridas na economia devido a mudanças nos gastos públicos, redução de gasto corrente e principalmente aumento do gasto em investimento. Esse segundo interfere diretamente na economia, pois é um fator produtivo essencial, e como o atual estoque de capital público é aquém do ideal calculado anteriormente, sua elevação provoca aumento no produto. Logo, desde que esse aumento não seja financiado por um aumento de tributos, que é prejudicial à produção, seus efeitos serão somente benéficos para a economia, o que ocorre nas simulações 1 e 2 , mas essa reforma não será facilmente implementada pela administração pública caso haja queda da arrecadação e necessidade de redução de gastos, em termos reais.

$\mathrm{O}$ crescimento econômico e consequente ampliação da base tributária é suficiente para não haver necessidade de redução do consumo público em termos reais no primeiro cenário, mesmo que a parcela desse gasto em relação ao PIB caia para 18\%. Já a segunda simulação, que financia esse aumento de investimento via redução da parcela orçamentária destinada a outros gastos provoca redução real de $6 \%$ nessa rubrica, que inclui principalmente a previdência e o pagamento de juros, gastos esses muito rígidos. Dessa forma, essa reforma seria de dificil implantação. A terceira é mais favorável para o 
governo, que financia o aumento do investimento com elevação da carga tributária, aumentando sua receita em $19 \%$ e o consumo em $13 \%$. Mas como dito anteriormente, o aumento das alíquotas provoca efeito negativo, reduzindo a acumulação de capital e o produto, sendo essa a simulação com menores resultados do ponto de vista produtivo e de bem-estar.

Por fim, a simulação quatro exige uma ampla reforma administrativa capaz de diminuir o consumo do governo em $7 \%$. A redução das alíquotas altera a carga tributária para $30 \%$ do PIB, impondo uma perda real de $8 \%$ da arrecadação. Esses não são resultados favoráveis para o setor público, que teria que reduzir muito seus gastos correntes e os outros gastos (9\%), e perderia arrecadação, pois o crescimento da economia não seria suficiente para superar a redução das alíquotas. Mas nesse cenário, o investimento público não precisaria sofrer redução, e essa redução do tamanho do Estado aumentaria o produto de equilíbrio em $3 \%$ e o bem-estar em $2 \%$, resultados não muito significativos.

Tabela 5: Resultados fiscais

\begin{tabular}{lccccccc}
\hline & \multirow{3}{*}{ Carga tributária } & \multicolumn{3}{c}{ Gasto público (\% PIB) } & \multicolumn{3}{c}{ Variações } \\
\cline { 3 - 8 } & & Consumo & Investimento & Outros & Receita & Consumo & Outros \\
\hline 2010 & 33,56 & 20,22 & 1,89 & 11,46 & - & - & - \\
1 & 33,21 & 18 & 3,75 & 11,46 & 11,89 & 0,66 & 13,08 \\
2 & 33,21 & 20,22 & 3,75 & 9,23 & 15,59 & 16,83 & $-5,84$ \\
3 & 35,43 & 20,22 & 3,75 & 11,46 & 18,87 & 12,61 & 12,6 \\
4 & 30 & 18 & 1,89 & 10,11 & $-8,24$ & $-8,62$ & $-9,37$ \\
\hline
\end{tabular}

Fonte: Elaboração própria.

Ressaltamos que os resultados favoráveis das três primeiras simulações se devem ao aumento do fator "capital público" que aumenta a produtividade do capital privado elevando significativamente a produção. Mas as funções do Estado estão sendo redefinidas, as obrigações nas áreas sociais são muito maiores, e talvez não haja espaço para elevação de investimentos públicos, mas o governo precisa investir em infraestrutura ou proporcionar condições para que o setor privado supra essa necessidade da economia.

\section{CONSIDERAÇÕES FINAIS}

Este trabalho buscou analisar qual deveria ser o tamanho do governo e quais os efeitos dessa diminuição do Estado sobre a economia.

Utilizando dados de 136 países, buscamos comparar os gastos públicos e os indicadores sociais do Brasil com economias semelhantes, e a análise empírica demonstrou que o consumo final das administrações públicas é maior do que deveria ser, hoje tal rubrica representa $20 \%$ do PIB, enquanto o modelo calcula que tal gasto deveria estar entre 15 e $18 \%$. Uma simples comparação de médias mostra que apesar do Brasil arrecadar como país desenvolvido, apresenta indicadores econômico-sociais menores que os demais países emergentes, ou seja, apesar do enorme esforço fiscal, o governo não devolve à sociedade bens e serviços suficientes.

O segundo resultado obtido neste trabalho é que o gasto público em bens de capital está demasiadamente baixo, e o ótimo seria aumentar a razão investimento público/produto dos atuais 1,89\% para $3,75 \%$, o que representa um aumento real de mais de $100 \%$ no investimento público. Assim como a alteração do consumo do governo, essa é uma mudança de difícil execução, e talvez outras políticas de desenvolvimento industrial e de estímulo à poupança produzam resultados semelhantes, não pre- 
cisando o Estado alterar tanto sua estrutura de gastos. Mas lembramos que essa variável representa o capital público, a infraestrutura da economia, essencial à produção e responsável por aumentar a produtividade do capital privado, ao melhorar o sistema de transportes, rodovias, portos e aeroportos, comunicação, energia, e esses são bens que dificilmente o mercado conseguirá ofertar de forma ótima.

Por fim, foram realizadas simulações buscando identificar os efeitos de reformas administrativas e fiscais na economia. Primeiro analisamos os efeitos do aumento da taxa de investimento do setor público e três formas de financiamento, as duas primeiras a partir de uma reforma administrativa, que reduzia as outras duas rubricas dos gastos públicos e a terceira via aumento de tributação. Os resultados sugerem que a elevação do investimento público financiado pela redução do gasto corrente é muito benéfica para a economia, o financiamento através da redução dos outros gastos não é factível para o setor público, e o aumento da tributação reduz os efeitos positivos da elevação do capital público.

A redução do consumo do governo sem a elevação do investimento público favorece a economia ao reduzir a tributação, mas não provoca grandes alterações na base tributável (trabalho, consumo e capital) o que reduziria a arrecadação e imprimiria uma queda acentuada do consumo público, ambos em termos reais. Apesar de não ser favorável para o governo, tal alteração seria benéfica para as famílias ao aumentar o consumo e o bem-estar.

É importante ressaltar que esse exercício simula efeitos de longo prazo, desconsiderando as fricções que existem nos mercados no curto prazo, como pressões inflacionárias advindas do aumento da demanda agregada por elevação do investimento, tanto público quanto privado. Outra limitação do trabalho se situa nas hipóteses adotadas na construção do modelo empregado, questões como abertura da economia, diferenciação de setores produtivos e efeitos distributivos precisam ser considerados, havendo necessidade de novas pesquisas que foquem nesses pontos específicos.

Este trabalho simula mudanças radicais que dificilmente serão realizadas, principalmente no curto e médio prazo. O Estado brasileiro possui muitas obrigações rígidas, com pessoal, previdência, saúde, pagamento de juros, despesas que constitucionalmente não podem sofrer reduções. E também há muitas obrigações em áreas sociais que apresentam grande carência de investimentos. As mudanças sugeridas aqui são extremas, mas qualquer redução que o governo fizer abrirá espaço para redução da tributação. Em relação ao capital público, caso o governo não encontre possibilidade de investir precisará estimular o setor privado, e nesse sentido o Programa de Aceleração do Crescimento (PAC) lançado em janeiro de 2007 foi um grande avanço.

A reforma fiscal é amplamente discutida, mas o outro lado do Governo também precisa ser debatido. Tornar o sistema tributário eficiente, tentar reduzir a carga imposta à sociedade, só é possível com as mesmas ações para os gastos públicos: esses precisam se tornar mais eficientes e menores.

\section{BIBLIOGRAFIA}

Anuatti-Neto, F., Barossi-Filho, M., Carvalho, A. G., \& Macedo, R. (2005). Os efeitos da privatização sobre o desempenho econômico e financeiro das empresas privatizadas. Revista Brasileira de Economia, 59:151-175.

Aschauer, D. A. (1989). Is public expenditure productive? Journal of Monetary Economics, 23:177-200.

Assis, L. C. \& Dias, J. (2004). Política fiscal, nível tecnológico e crescimento econômico no Brasil: Teoria e evidência empírica. In Anais do XXXII Encontro Nacional de Economia, João Pessoa. ANPEC.

Banco Mundial (2006). Relatório “World Development Indicators”. www . worldbank . org.

Barro, R. J. (1989). Cross-country study of growth, saving and government. Working Paper 2855, NBER.

Barro, R. J. (1990). Government spending in a simple model of endogenous growth. Journal of Political Economy, 98:s103-s125. 
Chamley, C. (1986). Optimal taxation of capital income in general equilibrium with infinite lives. Econometrica, 54:607-622.

CIA (2006). Relatório “The world factbook”. Central Inteligency Agency. www . cia .gov.

Cândido Jr, O. (2001). Os gastos públicos no Brasil são produtivos. Planejamento e Políticas Públicas 23, IPEA, Rio de Janeiro.

Easterly, W. \& Rebelo, S. (1993). Fiscal policy and economic growth. Journal of Monetary Economics, 32:417-458.

Evans, P. \& Karras, G. (1996). Private and government consumption with liquidity constraints. Journal of International Money and Finance, 15:255-266.

Ferreira, P. C. \& Araújo, C. H. V. (1999). Reformas tributárias no Brasil: Efeitos alocativos e impactos de bem-estar. Revista Brasileira de Economia, 53:133-166.

Ferreira, P. C. \& Malliagros, T. G. (1998). Impactos produtivos de infraestrutura no Brasil, 1950-1995. Pesquisa e Planejamento Econômico, 2:315-338.

Ferreira, P. C. \& Nascimento, L. G. (2006). Welfare and growth of alternative fiscal rules for infrastructure investment in Brazil. Ensaios Econômicos 604, EPGE, Rio de Janeiro.

Feu, A. (2001). Evolução da razão capital/produto no Brasil e nos países da OCDE. Seminários, DIMAC/IPEA.

Gremaud, A. P., Vasconcelos, M. A. S., \& Toneto Jr, R. (2004). Economia Brasileira Contemporânea. Atlas, São Paulo, 5a. edition.

IBGE (2010). Pesquisa nacional por amostra de domicílios 2009. Brasília.

IBGE (2011). Sistema de contas nacionais 2010. Instituto Brasileiro de Geografia e Estatística. www . ibge.gov.br.

Morandi, L. \& Reis, E. J. (2005). Estoque de capital fixo no Brasil 1950-2001. Seminário de pesquisa, EPGE.

Paes, N. L. \& Bugarin, M. N. S. (2006a). Parâmetros tributários da economia brasileira. Estudos Econômicos, 36:699-720.

Paes, N. L. \& Bugarin, M. N. S. (2006b). Reforma tributária: Impactos distributivos, sobre o bem estar e a progressividade. Revista Brasileira de Economia, 60:33-56.

PNUD (2006). Relatório de desenvolvimento humano. Programa das Nações Unidas para o Desenvolvimento. www. undp. org.

Samuelson, P. A. (1954). The pure theory of public expenditure. Review of Economics and Statistics, 36:387-389.

Silva Filho, T. N. T. (2001). Estimando o produto potencial brasileiro: Uma abordagem de função de produção. Trabalhos para Discussão 17, Banco Central do Brasil.

UNESCO (2006). Organização Educacional, Científica e Cultural da Nações Unidas. www . unesco . org. 


\section{A. ANEXO - ANÁLISE DE SENSIBILIDADE DOS PARÂMETROS}

Os parâmetros $(\gamma)$ que mede a produtividade do fator capital público e $(\mu)$ que representa o peso dado pela família ao consumo público em sua função utilidade não são consensuais na literatura. Os demais parâmetros foram calibrados com dados das Contas Nacionais, Receita Federal ou calculados pelas equações do modelo e refletem a atual realidade da economia brasileira.

A produtividade do capital público é de suma importância no modelo, pois se essa for zero, não seria necessário o acúmulo de tal fator, e com o aumento do valor de tal parâmetro, maior o produto dado o mesmo nível de capital público. Logo, é interessante analisar a sensibilidade dos resultados das simulações dado alterações nesse parâmetro.

Mas o cálculo da taxa de investimento ótima do setor público leva em consideração $(\gamma)$, e como o valor encontrado já é elevado, mais que o dobro do atual, iremos manter a taxa de investimento pública calculada em 4.1 e vamos variar o parâmetro no cálculo do estado estacionário antes e depois da reforma simulada. Na Tabela A1 se encontra a variação do novo estado estacionário em relação a situação inicial de quatro agregados macroeconômicos, produto, consumo privado, consumo público e bem-estar.

Observamos nas três primeiras simulações que os resultados são sensíveis a variação da produtividade do capital, sendo esse resultado esperado, uma vez que o capital público é essencial na produção e não há congestionamento em seu uso, sua produtividade interfere fortemente no nível de produção da economia. Mas mesmo considerando uma produtividade menor $(\gamma=0.05)$ ainda observamos ganhos de bem-estar no longo prazo, a única alteração seria a redução do consumo do governo na simulação 1 , que não seria necessário com valores maiores desse parâmetro. Por fim, observando a simulação 4 onde não há alteração da taxa de investimento público, observamos que os resultados não sofrem grandes alterações, mostrando a baixa sensibilidade do modelo básico a variações desse parâmetro.

Tabela A1 - Análise de sensibilidade da produtividade do capital público

\begin{tabular}{|lllccc}
\hline & & \multicolumn{4}{c}{ Simulação } \\
\cline { 3 - 6 } 0 & & 1 & 2 & 3 & 4 \\
0,05 & Produto & 6,29 & 9,53 & 5,87 & 2,45 \\
& Consumo privado & 6,9 & 6,25 & 2,96 & 5,71 \\
& Consumo público & $-5,39$ & 3 & 2 & $-8,8$ \\
& Bem-estar & 3,25 & 9,53 & 5,87 & 1,88 \\
& & & & & \\
\cline { 3 - 7 } 0,09 & Produto & 13,09 & 16,83 & 12,61 & 2,66 \\
& Consumo privado & 13,73 & 13,33 & 9,5 & 1,09 \\
& Consumo público & 0,66 & 16,83 & 12,61 & $-8,62$ \\
& Bem-estar & 6,82 & 6,58 & 5,51 & 2 \\
& & & & & \\
0,15 & Produto & 26,86 & 31,66 & 26,24 & 3,04 \\
& Consumo privado & 27,6 & 27,73 & 22,78 & 6,32 \\
& Consumo público & 12,92 & 31,66 & 26,24 & $-8,28$ \\
& Bem-estar & 12,89 & 12,66 & 11,47 & 2,23 \\
\hline
\end{tabular}


Em relação ao parâmetro $(\mu)$, sua alteração somente modificará o valor da utilidade e consquentemente a variação de bem-estar, logo, apresentamos somente esse resultado. Na Tabela A2 vemos que para os três valores de $(\mu)$ mencionados no texto, as variações de bem-estar são muito próximas, sendo que nas simulações onde há redução do consumo público (1 e 4), quanto maior o valor do parâmetro, mais importância a família atribui a esse dispêndio, e menor a variação de bem-estar.

Tabela A2 - Análise de sensibilidade do peso do consumo público - Variação do bem-estar

\begin{tabular}{cccccc}
\hline & & \multicolumn{4}{c}{ Simulação } \\
\cline { 3 - 6 } & & 1 & 2 & 3 & 4 \\
& 0 & 7,71 & 6,35 & 5,29 & 3,2 \\
& 0,5 & 6,82 & 6,58 & 5,51 & 2 \\
& 1 & 6,12 & 6,76 & 5,67 & 1,07 \\
\hline
\end{tabular}

